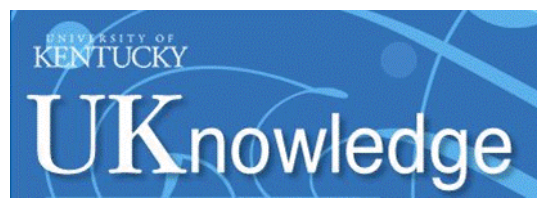

University of Kentucky

UKnowledge

$1-2013$

\title{
Investigation of Turbulent Structure Modification by Momentum Injection Into Turbulent Flow Over a Rough Surface
}

\author{
Mark A. Miller \\ University of Kentucky \\ Huaibao Zhang \\ University of Kentucky, paulhuaizhang@uky.edu \\ Alexandre Martin \\ University of Kentucky, alexandre.martin@uky.edu \\ Sean C. C. Bailey \\ University of Kentucky
}

Follow this and additional works at: https://uknowledge.uky.edu/me_facpub

Part of the Aerodynamics and Fluid Mechanics Commons

Right click to open a feedback form in a new tab to let us know how this document benefits you.

\section{Repository Citation}

Miller, Mark A.; Zhang, Huaibao; Martin, Alexandre; and Bailey, Sean C. C., "Investigation of Turbulent Structure Modification by Momentum Injection Into Turbulent Flow Over a Rough Surface" (2013). Mechanical Engineering Faculty Publications. 15.

https://uknowledge.uky.edu/me_facpub/15

This Conference Proceeding is brought to you for free and open access by the Mechanical Engineering at UKnowledge. It has been accepted for inclusion in Mechanical Engineering Faculty Publications by an authorized administrator of UKnowledge. For more information, please contact UKnowledge@lsv.uky.edu. 


\section{Investigation of Turbulent Structure Modification by Momentum Injection Into Turbulent Flow Over a Rough Surface}

Digital Object Identifier (DOI)

http://dx.doi.org/10.2514/6.2013-534

\section{Notes/Citation Information}

Published in the Proceedings of the 51st AIAA Aerospace Sciences Meeting including the New Horizons Forum and Aerospace Exposition, Paper 2013-0534, p. 1-10.

Copyright (C) 2013 by Sean Bailey.

The copyright holder has granted the permission for posting the article here. 


\title{
Investigation of Turbulent Structure Modification by Momentum Injection Into Turbulent Flow Over a Rough Surface
}

\author{
Mark A. Miller, "Iluai-Bao Zhang;* \\ Alexandre Martin ${ }^{\dagger}$ and Sean C. C. Bailey \\ 1)epartment of Mechanical Engineering, University of Kenturky, Lexington, $K Y, 40506$, USA
}

\begin{abstract}
Utilizing a turbulent, channel flow facility, experiments were performed to determine the modifications made to the temporal and spatial structure of turbulence over a sinusoidally rough surface due to momentum injection through the surface. As expected, when compared to the smooth-walled conditions, it was found that the surface roughness increased wall shear stress, decreased the turbulence energy content near the wall, and shifted that energy content to wavelengths on the order of the roughness elements. The addition of momentum injection was found to produce further modifications analogous to increasing the roughness height by increasing the wall shear stress and further reducing the energy content of the near-wall turbulence while simultancously shifting it to longer wavelengths.
\end{abstract}

\section{Nomenclature}

Symbols

Density, $\mathrm{kg} / \mathrm{m}^{3}$

Chammel half height, $m$

Kinemalic viscosily $\mathrm{ml}^{2} / \mathrm{s}$

Streamwise direction

Wall normal direction

Pipe diameter, $m$

Prossure, Pa

Area averaged velocily, $\mathrm{m} / \mathrm{s}$

Thurbulence intensity, $\mathrm{m} / \mathrm{s}$

$\begin{array}{ll}R_{e_{h}} & \text { Reynolds number based on hall height } \\ R_{c_{\tau}} & \text { Reynolds number based on friction velocity }\end{array}$

$k_{r}$ Roughness Reynolds number

$c_{f} \quad$ Coefficient of friction

$K$ Pressure loss coefficient

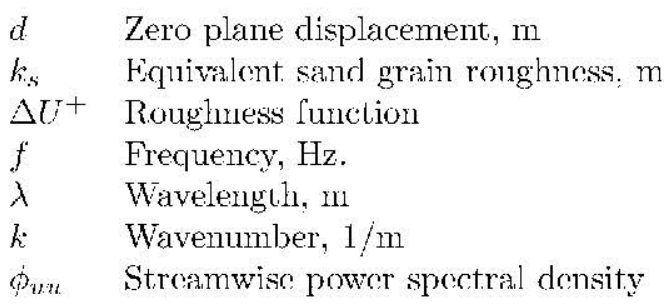

Subscripts

cl Channel centerline

inj Injected flow characteristic

$x$ Property of streanwise direction

I Scaling with friction velocity

Overbar indicates time average

\section{Introduction}

Ablative materials for use in thermal protection systems (TPS) have a very successful track record as an effective heat shield material when the most demanding re-entry conditions are encountered. Ablative TPS systems can be divided into two types: charring (or pyrolizing) and non-charring. The principle behind the use of charring ablators is simple: energy absorbed through removal of material from the surface is not used

\footnotetext{
"Graduate Research Assistant. Merhanical Fngineering. ATA A Student Member

$\dagger$ †ssistant Professor, Mechanical Engineering, $A \mathrm{I} A \mathrm{~A}$ Member.

¥ Assistant. Professor, Mechanical Engineering.
} 
to heat the TPS, therby keeping it at a lower temperature. In the case of charring ablators, the ablative material is a resin that fills the pores of a carbon matrix. Although the matrix might ablate, it usually does not, thus producing an aerodynamic surface consisting of a sparse, porous geometry during re-entry.

Many physical phenomena oceur during ablation of a 'T'PS which must be modeled correctly when designing re-entry systems. For exannple, pyrolysis chemistry within the TPS and the low of pyrolysis gas through the porous surface. The near-wall flow field is affected by the chemical species emitted from the ablating surface and injected into the near-wall hlow. The presence of this ablation gas greatly reduces the heat flux on the vehicle by: (1) thickening the thermal boundary layer and reducing the temperature gradient near the wall; (2) changing the gas composition near the wall which triggers chemical reactions; and (3) injection a relatively cooler gas into the flow field. The complexily of the processes which must be modeled leads to uncertainty when designing a TPS and requires generous margins of safety. Furthering our understanding of pyrolizing ablator physics has the potential to lead to innprove the safety of TFS designs while reducing launch costs through weight reduction.

The key element in a properly functioning charring ablator is the flow of pyrolysis gases from the surface into the boundary layer. Any modeling effort concerning the design of ablative material TPS nust therefore take into account flow injection and its effect on the heat flux to the vehicle. Additionally, the TPS surface geometry must be accurately modeled, which is complicated by roughening of the char surface and possible: material removal by thermomechanical erosion. ${ }^{5}$ This roughness also introduces disturbances in the flow ficld which can lead to transition to turbulenee, particularly for larger TPS surfaces. Thrbulent flow over a TPS surface will drastically increase the transport of mass: nomentum and energy between the surface and the flow field and therefore improving our ability to model the turbulent physics of the near-wall flow during charring ablation is crucial to understanding these transport processes.

Extensive work has been completed on roughness induced turbulence, $6 \pi, 14,15,21,25$ although there is still no methodology for predieting turbulent. flow behavior over an arbitrary surface roughness topology. ${ }^{32}$ There has also been extensive work performed on turbulent transition where flow injection is present. ${ }^{20,23}$ Surprisingly, however, there have been very few studies combining both the effects of blowing and of roughness on turbulent boundary layers. " The current set of experiments aim to improve our understanding of how these two parameters modify the structure of turbulent flow forming over the surface.

Here we present results from an experiment conducted in a turbulent channel flow wind tunnel to investigate the near-wall turbulence over a sinusoidally rough, nicro-perforated surface, both with and without flow injection through the surface. These measurements are believed to be the first quantification of turbulence statisties for flows combining the effects of both roughness and blowing.

\section{Experiment Description}

The experiments were performed in the Turbulent Channel Flow Facility (TCFF) at the Lniversity of Kentucky's Fixperimental F'uid J)ynamies Jaboratory (FFJ)L). 'The 'TCFF' has been earefully designed to produce fully developed turbulent, plane Poiseuille low at centerline how velocities of up to $U_{c l}-45 \mathrm{~m} / \mathrm{s}$ corresponding to a maximum Reynolds number based on half height of $R_{c_{h}}=h U_{c l} / \nu=150,000$, where $\nu$ is the kinematic viseosity and $h$ is the channel half-height of $h=0.0508 \mathrm{~m}$. The channel has an aspect ratio of 9:1 to ensure quasi-2D flow at the centerline ${ }^{20}$. The distance from the channel inlet to the test section is $280 h$, allowing the turbulenee to reach a fully-developed state naturally ${ }^{i}$ before entering the channel test section, $246 h$ downstream of the inlet.

For this set of experiments, a $24 h$ long section of the smooth-walled test section roof was replaced by a nominally two-dimensional, sinusoidally varying rough surface with a streamwise wavelength of $\lambda=7 \mathrm{~mm}$ and an amplitude of $0.4 \mathrm{~mm}$ pictured in Fig. 1. This surface is micro-perforated to allow for additional injection of gases into the test section. Flow is driven through the surface by ten $14 \mathrm{~W}$ Sofasco SF'12038 highnow fans which pressurize the upper plenurn of the blowing apparatus (Fig. 2). The blowing apparatus is further equipped with two lower sections, separated by screens and flow straightening honeycombs, designed to break down large-scale disturbances introdueed by the fans. This ensures an even, laminar injoction of air across the rough surface. The first sereen is composed of a 3 murn square mesh and the flow is allowed to decay $203 \mathrm{~mm}$ before reaching the flow straightener. The straightener is formed of thin ahluminum strips bonded in a honeycomb matrix. The flow travels $50 \mathrm{~mm}$ through the straightener and past the second screen of square mesh size $1.5 \mathrm{~mm}$. Finally, the flow decays an additional $100 \mathrm{~mm}$ before reaching the rough surface.

In order to characterize the injection rate into the test section from the blowing apparatus, the blowing 


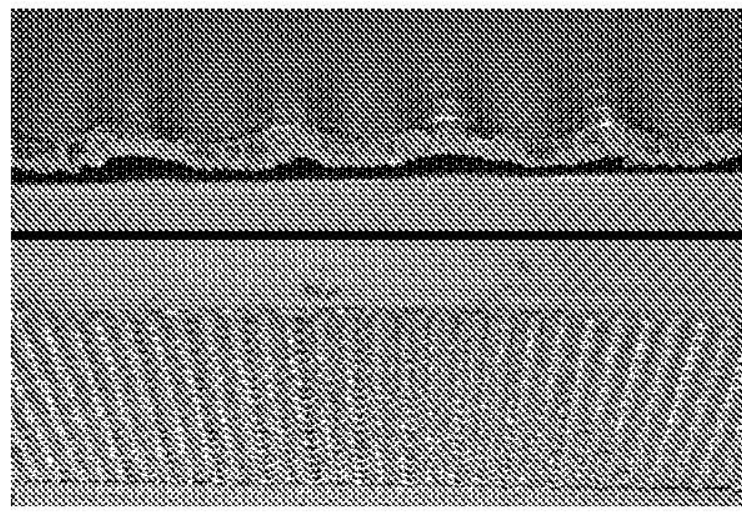

Figure 1. Sinusoidal surface roughness with micro-cracked pores visible

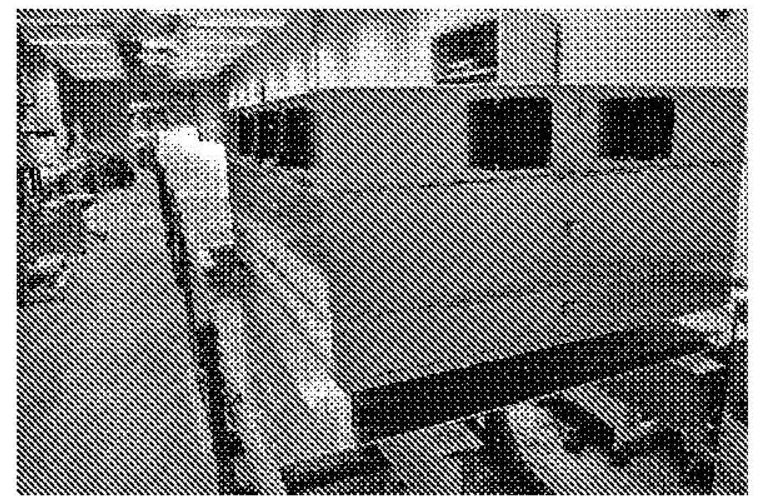

Figure 2. Blowing apparatus mounted above test section of TCFF

ratio $B R$. was defined as

$$
B R=\frac{(\rho U)_{i n j}}{(\rho U)_{c l}}
$$

where $U_{i n j}$ indicates the average velocity of the flow injected through the surface and $U_{a l}$ the mean centerline velocity. To determine $B R$, the blowing rig was designed with eight pressure taps located circumferentially around the blowing apparatus in sets of four. One set is located midway between the flow conditioning screens and the second set is located between the bottom screen and the rough surface. The bottom set of taps, together with a measurement of the static pressure in the channel test section are used to determine the mean injected flow velocity using the loss coefficient.

$$
K-\frac{\Delta p}{1 / 2 \rho U_{i n j}{ }^{2}}
$$

where $\Delta p$ the measured pressure drop across the sereen. ${ }^{25}$ The value of $K$ for the test surface provided a novel way of determining the very low low rates experienced through the rough surface and was determined through a separate set of experiments conducted in a pipe flow facility constructed specifically to determine $K$. The pipe was constructed of smooth PVC, wilh a dianeter, $D-50.8 \mathrm{~mm}$. The pipe was pressurized at one end and the flow rate regulated via a ball valve. The flow entered the pipe and was allowed to develop along a length of $295 \mathrm{~J}$ ) before entering the test section. The insertion of a porous test specimen was performed with specially designed plugs which positioned the test specimen in the pipe but did not allow for pressurized air to escape the pipe. This test section was followed by a further $100 \mathrm{D}$ of pipe to allow for pressure measurements after the test article. The pipe was fitted with pressure taps ${ }^{20}$ which allowed for determination of the pressure drop across the test article and along the pipe section. The velocity profile at the pipe out let was also measured using a Pitot-static tube mounted on a traverse. To characterize $K$, the inlet pressure was varied and the the pressure drop across the sample and nnean exit velocity were recorded.

Turbulence measurements were conducted in the TCFF at 10 wall-normal positions inside the channel using a single-component hot-wire anemometer (HWA) due to its ability to temporally resolve the streamwise turbulent fluctuations. The HWA probes were operated at an overheat ratio of 1.6 , resulting in a measured square-wave response above $70 \mathrm{kHz}$. The anemometer output was then analog filtered at $30 \mathrm{kHz}$ and digitized at a rate of $60 \mathrm{kIIz}$ for $120 \mathrm{~s}$ long samples using a 16-bil data acquisition system (National Instruments PCI6123). Probe calibrations were performed in-situ directly prior to measurement runs in the chamel itself using a Pitot probe located at the channel enterline connected to a NIST calibrated pressure transducer (Omega PX-653). Measured bridge voltages were then corrected for any temperature fluctuations ${ }^{1 ?}$ as measured by a thermistor probe located in the tumnel (Omega T'HX-400) and a fourth order polynomial used to fit the calibration curves. This process leads to an estinated uncertainty of $2.2 \%$ in the mean velocily and $3.0 \%$ in the streamwise Reynolds stress. To capture the wall-normal streamwise velocity profile, the probes were mounted on a microstepping traverse. For the rough walled cases, the probes were traversed into the wall and destroyed to ensure accurate capture of the wall position and to provide measurements from within the ronghness layer.

Measurements have been conducted at a single Reynolds number of $R_{e_{n}}-35,000$ al four values of $B R$. corresponding to $0 \%, 0.15 \%, 0.25 \%$, and $0.37 \%$. These results were compared to two sets of data from 
the same facility with the smooth-walled surface in place. Smooth data set "A" matches the free-stream velocity of the test cases: $U_{c l}-10.5 \mathrm{~m} / \mathrm{s}$, and smooth dala set " $\mathrm{B}$ " malches the friction Reynolds nurniber: $h_{e_{\tau}}=h u_{\tau} / \nu$, where $u_{\tau}=\sqrt{\tau_{w} \rho^{-1}}$ is the friction velocity. For the smooth wall data sets, the friction velocity was determined by performing a simple momentum balance ${ }^{-9}$ in the channel whereby

$$
u_{\tau}=\left[(1 / \rho) \epsilon_{T} \frac{h}{2} \frac{d p}{d x}\right]^{1 / 2}
$$

Here $\epsilon_{T}$ is a three-dimensionality factor equal to unity for flow in channels with sufficiently high aspect ratios" and $d p / d x$ is the measured pressure gradient. Due to lack of a suitable alternative, the Clanser chart method was used to find the friction velocities of the rough walled cases. ${ }^{7}$

\section{Results}

A rough surface geometry can be characterized in numerous ways. " However the specific influence of each geometrical surface elernent on the mean flow quantities is difficult to determine. Present in table 1 are a few of the defining attributes which have been found for this set of experiments. As indicated by the values in table 1 , the skin friction coefficient, $c_{f}-\tau_{w} /\left(\frac{1}{2} \rho U_{c l}^{2}\right)$, for the rough surface was approximately double that of the smooth-walled cases. As higher values of $c_{f}$ indicate faster shear layer growth, ${ }^{7}$ the increase in $c_{f}$ with increasing $B R$ suggests that the blowing acts to promote this shear layer growth.

\begin{tabular}{l|ccccc}
\hline Wall Type & $U_{c l}(\mathrm{~m} / \mathrm{s})$ & $R_{e_{h}} \times 10^{-3}$ & $u_{\tau}(\mathrm{m} / \mathrm{s})$ & $R_{e_{\tau}} \times 10^{-3}$ & $c_{f} \times 10^{3}$ \\
\hline Smooth A & 10.48 & 35.23 & 0.11 & 1.18 & 3.5 \\
Smooth B & 16.91 & 56.85 & 0.68 & 2.29 & 3.2 \\
Rough, $B R=0 \%$ & 10.46 & 35.16 & 0.63 & 2.12 & 7.2 \\
Rough, $B R-0.15 \%$ & 10.59 & 35.60 & 0.66 & 2.22 & 7.7 \\
Rough, $B R=0.25 \%$ & 10.33 & 34.73 & 0.68 & 2.29 & 8.4 \\
Rough, $B R=0.35 \%$ & 10.62 & 35.71 & 0.72 & 2.12 & 9.2 \\
\hline
\end{tabular}

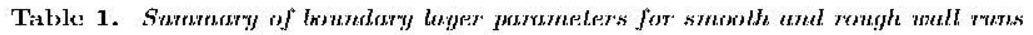

\section{II.A. Mean Flow Characteristics}

\begin{tabular}{l|cccc}
\hline Wall Type & $d(\mu \mathrm{m})$ & $\Delta U^{+}$ & $k^{+}$ & $k_{\mathrm{s}}(\mu \mathrm{m})$ \\
\hline Rongh, $B R=0 \%$ & 287 & 7.82 & 11.9 & 2.9 \\
Rough, $B R=0.15 \%$ & 370 & 8.12 & 12.4 & 3.5 \\
Rough, $B R-0.25 \%$ & 145 & 9.42 & 12.8 & 5.1 \\
Rongh, $B R=0.35 \%$ & 159 & 10.22 & 13.6 & 6.5 \\
\hline
\end{tabular}

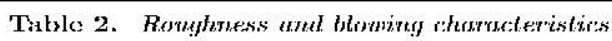

Studies on rough wall turbulent boundary layers indicate that a shift of the turbulene producing shear layer above the surface occurs wilh increasing roughness height Reynolds number, here defined as $k^{+}-$ $k_{r m s} u_{\tau} / \nu$ where $k_{r m s}$ is the rms roughness height. $3,4, n, 27$ This shift, $d$, is referred to as the zero-plane displacement. ${ }^{21}$ In these experiments the value of $d$ was deternined by the oflset of the region of near-zero streamwise Reynolds stress measured under conditions of roughness and blowing. For the remainder of this paper, wall normal distance is presented as $Y=y-d$, where $y$ is the physieal distanee from the wall. The different values of $d$ used are provided in table 2.

Also provided in table 2 is the roughness Reynolds number $k^{+}$, and the equivalent sand-grain roughness height, $k_{s}$, as defined by Raupach ${ }^{2 \mathrm{i}}$ for example. The flow regine was linited to the transitional, $5<k^{+}<$ 70. Interestingly, we see that the effects of additional momentum injection act through an increase in the effective ronghness height and a corresponding increase in local wall shear stress.

In Fig. 3 the mean velocity profiles, $U(Y)$, are presented using different nomalizations. In Fig. 3(a) and (b), the profiles are compared using bulk properties $h$ and $U_{c l}$ for normalization, which illustrates the 


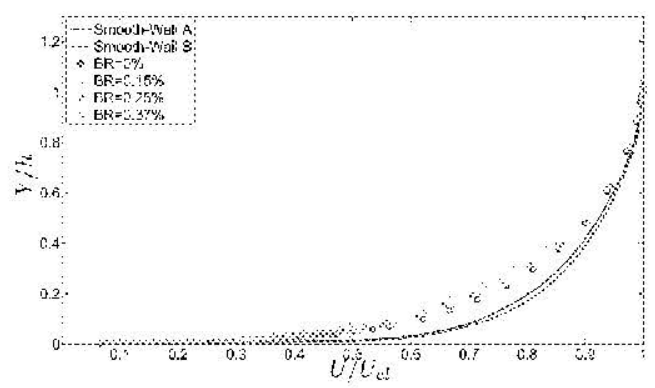

(a)

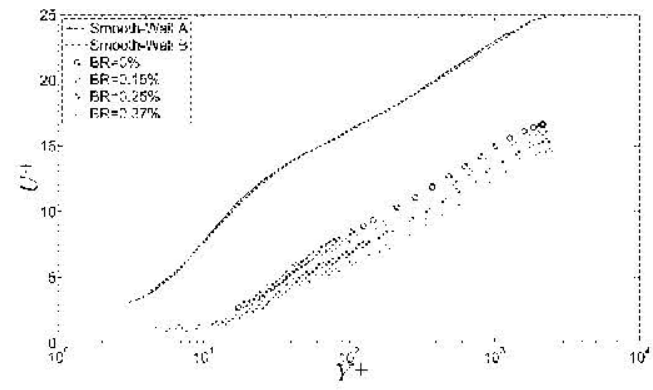

(c)

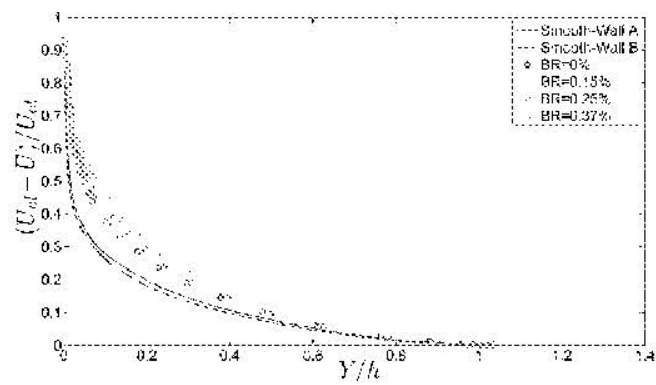

(b)

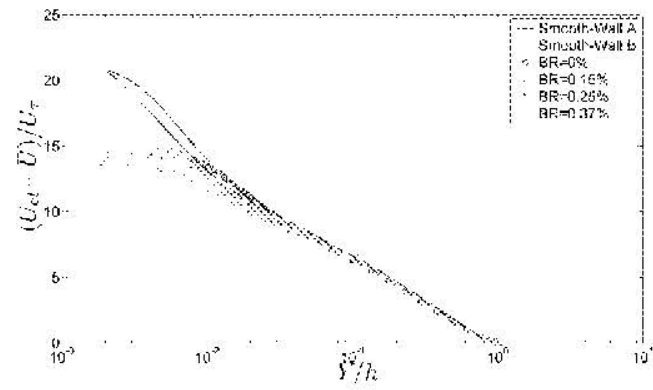

(d)

Figure 3. Mean velocity profiles non-dimensionalized using (a) bulk properties, (b) velocity deficit using bulk properties, (c) inner scaling and (d) outer scaling.

expected trend of the roughness and blowing making the profiles "less full" compared with the smooth wall case and it is evident that the effects of roughness are evident throughout the entire wall layer.

The mean velocity profiles shown in inner scaling where $U^{I}=U / u_{\tau}$ and $Y^{I}=Y u_{\tau} / \nu$ verify that one of the most interesting results observed in compressible how ${ }^{2 z}$ were also evident in inconpressible llow. Namely: these results show that the mean velocity profile follows

$$
U^{+}=\kappa^{-1} \ln Y^{+}+B-\Delta U^{+}\left(k^{+}\right)+11 \kappa^{-1} W(Y / h)
$$

as illustrated in Fig. 3(c). Here $\kappa$ is the von Kàrmàn constant, $B$ an additive constant, $\Pi \kappa{ }^{1} W(y / h)$ the wake function. Note that this sealing is driven by the wall shear stress, $\tau_{w}$. The effects of roughness on the mean flow are typically contained within the roughness function, $\Delta U^{\prime}\left(k^{\prime}\right),{ }^{21}$ which is itself dependent on the roughness Reynolds number, $k^{+}$. T'he estimated values of the $\Delta U^{+}$for each case are provided in table 2 .

The profiles shown in Fig. 3(c) demonstrate that the momentum injection through the surface can be treated as a modification to $\Delta U^{+}$, suggesting an analogy between momentum injection ratio, $B R=$ $(\rho U)_{i n j} /(\rho U)_{c l}$, and increased roughness height. Further support for this observation is found in the ouler scaled profiles shown in Fig. 3(c) where collapse of all profiles is demonstrated for $Y / h>0.1$, the onter layer of the flow. Ilence the effects of additional blowing are consistent with Townsend's ${ }^{27}$ hypothesis in that, sufficiently far from the surface, the effects of roughness on the flow are confined to those caused by the modification of the wall shear stress. Note that, support for this argument is somewhat temuous with the present data sel since here the wall shear stress was determined via the Clauser chart method, which necessarily assumes the validity of Fiq. 4 .

\section{II.B. Strcamwise Reynolds Stress}

Profiles of the streanwise Reynolds stress, $\overline{u^{\prime 2}}$, are presented normalized using outer coordinates in Fig. $1(\mathrm{a})$ and in inner coordinates in Fig. $1(\mathrm{~b})$, where $u^{2 ।}=\overline{u^{\prime 2}} / u_{\tau}^{2}$. In both scalings, collapse of the rough-wall data for all values of $B R$ can be observed in the outer layer, although the smooth-walled profiles do not 

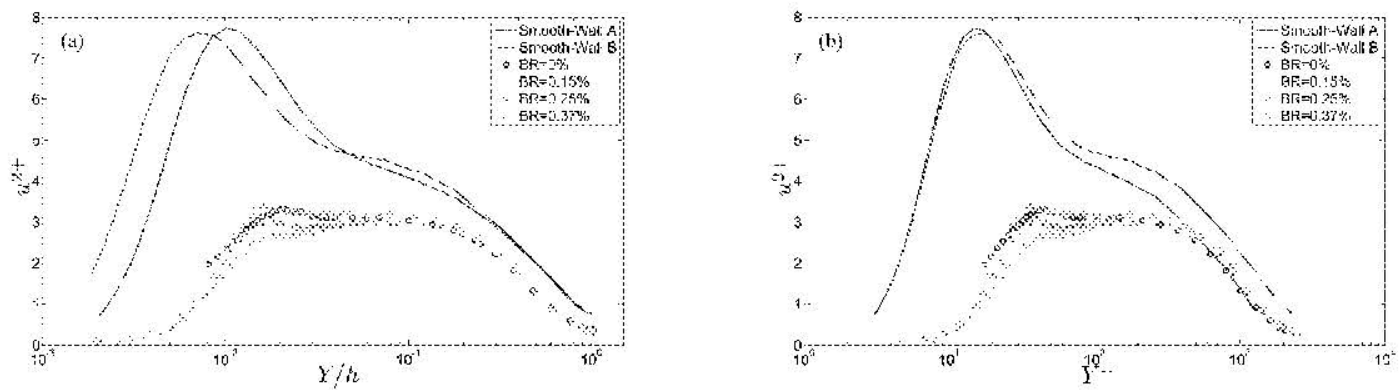

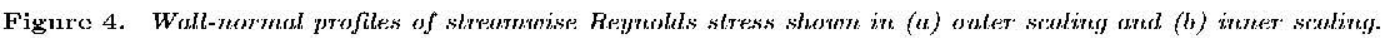

collapse with those of the rough surface. Closer to the surface, we observe an inner peak in wall shear stress for the rough-walled cases, similar to that of the smooth-walled case but with reduced magnitude. As the roughness Reynolds number increases, viscous forees are dominated by drag inducing pressure forees resulting in the observed decrease in the magnitude of the near wall peak.

For the rongh-walled eases, the location of the inner peak is shifted away from the wall, representing the shilt in turbulence production towards taking place in separated shear layers forming over the surface of the roughness elements. It can also be noted that neither scaling results in collapse of the inmer peak of the Roynolds stress with changing $B R$, with the magnitude of inner peak decreasing with increasing $B R$. T'his is consistent with the behavior expected due to increasing $k \mid$ and therefore provides further support for the effect of additional momentum injection aseting as an increase the effective roughness height.

\section{II.C. Streamwise Power Spectra}

Further insight into the modifications made to the spatial organization of the turbulence can be gained by examining the power spectrum. Here, this was performed using pre-multiplied spectral maps, as described in IIutchins and Marusic.:" To produce these maps, for each wall-nomal position linne series data were processed using a Fast-Fourier Transform (FFT) to generate the streamwise power spectral density (PSD). $\phi_{u u}(f, Y)$ and converted to wavemumber space using 'Taylor's hypothesis, $\phi_{u u}\left(k_{x}, Y\right)$ where $k_{x} \approx 2 \pi f / U$. 'The PSD was then pre-multiplied by the wavenumber to produce $k_{x} \phi_{u u}$. These premultiplied spectra were combined and are presented as spectral maps in Fig. 5, which have been normalized to show $k_{x} \phi_{u u u}(\lambda / h, Y / h) / u_{\tau}^{2}$ where $\lambda-2 \pi /\left(k_{x}\right)$. Figures $5(\mathrm{a})$-(e) therefore present the wavelength dependence of the contributions to the Reynolds stress, profiles of which are also included in Fig. 5 to better visualize which eddy wavelengths contribute to features observed in the Reynolds stress profiles. In particular, the results presented in Fig. 5 highlight the correlation between the near-wall peak of turbulence production in the Reynolds stress profiles and the corresponding peak (i.e. inner-energy site or near-wall signature) in the spectra, occurring at roughly $\lambda / h=0.1$ and $Y / h=0.01$. To better compare the differenees between the smooth-walled and rough-walled cases, the location of the near-wall peak in the pre-multiplied spectrum has been marked with a ( 1 ) for the smooth-wall case and an $(x)$ for the blowing cases.

For the smooth-walled case, the near-wall peak occurs at $Y / h-0.006\left(Y^{+}-Y u_{\tau} / \nu-13.7\right)$ and $\lambda / h=0.5\left(\lambda^{\prime}=\lambda u_{\tau} / \nu=1113\right)$. For the rough wall and blowing cases, as well as the previously observed shift in the peak away from the wall and decrease in magnitude of near wall peak, it is also evident that the roughness also shifts the near-wall energy containing signature from wavelengths of $\lambda \approx 0.6 h$ to $\lambda \approx 0.2 h$, which is approximately twice the streamwise wavelength of the roughness elements. T'his reflects a shift in turbulence production mechanism towards one driven by roughness geometry. Conpared to the $B R-0$ case, a continual decrease in the near-wall energy content is observed with increasing $B R$. This points to increased dismption of the near-wall turbulence production cycle present across multiple small wavelengths that scale with the roughness height of $1 \mathrm{~mm}$. However, despite experiencing a reduction in magnitude, the wavelengths and wall-normal location of the near-wall poak appears stationary across all blowing rates.

Also present in the spectral contours, extending out towards the larger wavelengths are the double humps or "dominant energy modes" as identified by, for example, Monty et al. ${ }^{\text {s. }}$ These modes have been established as the large and very-large scale motions (JSMs and VISMs). ${ }^{x-1,13,33}$ The formation of ISMs 


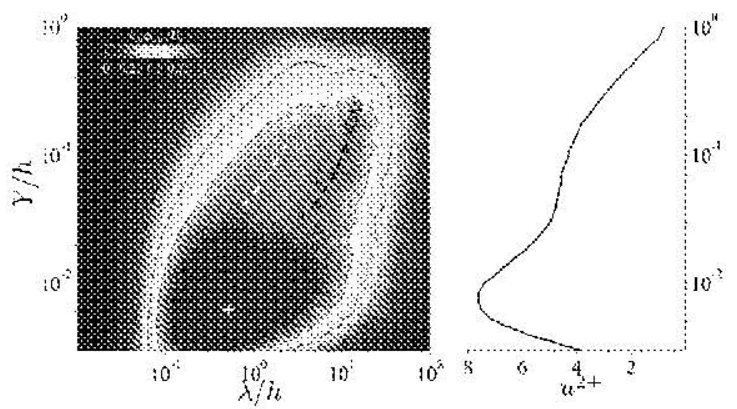

(a) Smooth Wall Case B

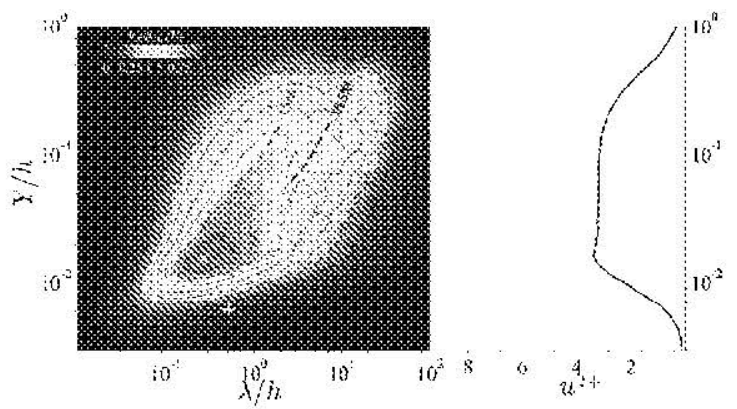

(c) Rough, $\mathrm{BR}=0.15 \%$

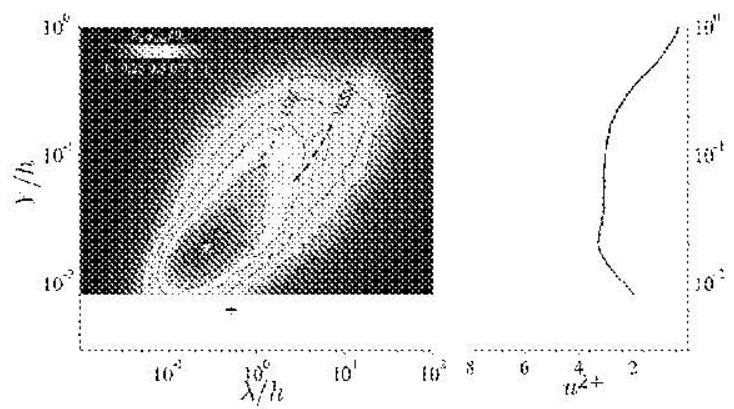

(b) Rough, $\mathrm{BR}=0 \%$

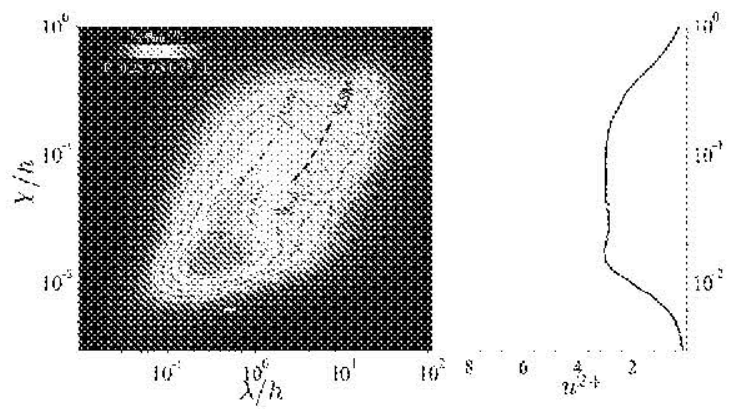

(d) Rough, $\mathrm{BR}=0.25 \%$

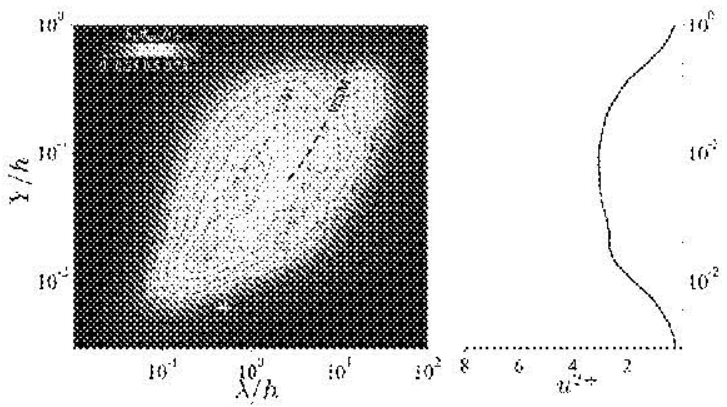

(e) Rough, BR=0.35\%

Figure 5. Pre-multiplied power spectral density plots, contour colors indicate the magnitude of $k_{m} \phi_{\omega_{w}} / u_{\tau}$

is thought to relate to the alignment of so-called "hairpin" vortices into packets. These packets exist in a heirarchy of larger, older LSMs and smaller younger LSMs. : Furthernore, very long meandering regions of low momentum fluid have been observed in chamel and pipe flow, ${ }^{3,2}$ referred to as "superstructures" or VISMs. These two modes have been hypothesized to contain as much as half the kinetic energy of the now ${ }^{2}$ and are therefore potentially important flow structures. The LSM and VLSM signatures have been identified with dashed lines in figure 5 and are observed in all cases. Although the energy content of the entire spectrun of the rough-walled cases, appears reduced relative to smooth-walled case due to the increase in skin friction relative as observed in other studies on roughness) $4,11,21$ the wavelengths of the LSM and VLSM appear relatively unchanged, with momentum injection appearing to produce no additional modification to the LSM and VLSM energy content.

To better compare the modifications to the energy content of the turbulence made by the momentum injection energy of the various blowing rates were generate we compare the differenee betwen the three blowing rates and the baseline no blowing case, $B R=0 \%$, by subtracting the spectral contour map Fig. $5(\mathrm{~b})$ from Fig. $5(\mathrm{c})-(\mathrm{c})$. The results are presented in Fig. 6(a)-(c) respectively and most noticeably highlight the changes made to the near-wall peak. These plots denonstrate that the decrease in energy content observed in the Reynolds stress profiles of Fig. 1 for all cases occurs at $\lambda \approx 0.15 h$, which is remarkably close to the 
wavelength of the roughness elements of $\lambda=0.14$. Therefore, it appears that the blowing is removing energy from eddies formed by the roughness elements. Simultaneously, a corresponding increase in energy can be observed at wavelengths an order of magnitude higher, reflecting a shift in turbulence production to that oceurring over longer wavelengths. This, onee again, is consistent with the momentum injection acting as a modificalion of effective roughness geometry.

Interestingly, Fig. 6 also shows changes in the LSM and VLSM structure with blowing: not previously evident in Fig. 5. This change in structure appears to consist of a decrease in energy content of the LSM wavelengths and a corresponding increase in VLSM wavelengths. These results suggest that there could be subtlo changes in the organization of these long wavelength modes towards longer wavelengths which corresponds to the shift in near wall peak towards longer wavelengths as well.

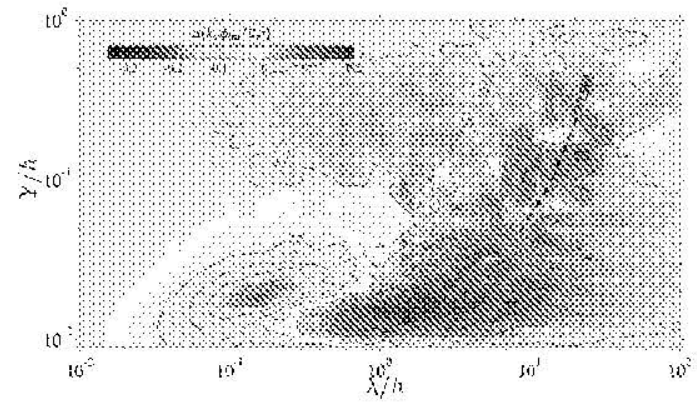

(a) $B R-0.15 \%$

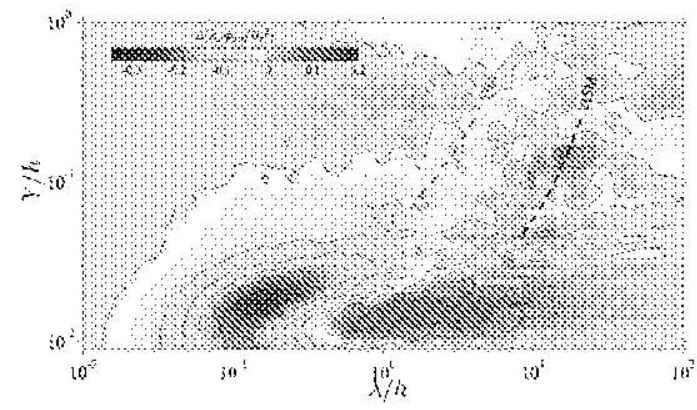

(b) $B R-0.25 \%$

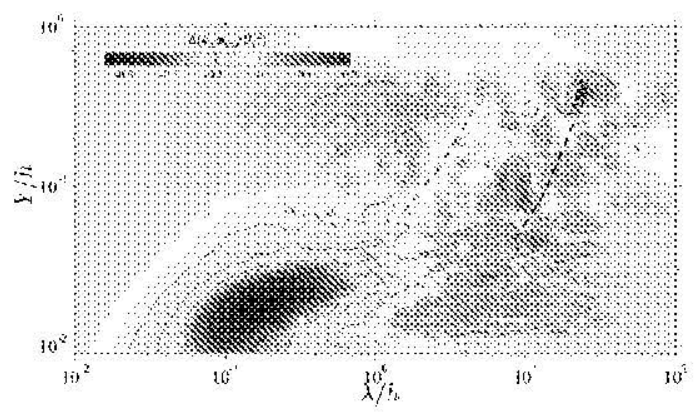

(c) $B R=0.37 \%$

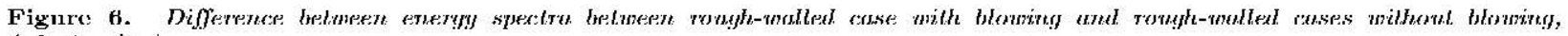
$\Delta k_{\mathrm{x}}, i_{\mathrm{u}} / u_{\mathrm{r}} \mathrm{l}$

\section{Conclusions}

Velocity measurements have been performed in turbulent channel flow investigating the corrbined effects of surface roughness and blowing. Scaling of the mean velocity profiles suggests that Townsend's hypothesis is supported even with momentum injection through the surface. Although comparison of the Reynolds stress profiles between the smooth-walled and rough-wall cases did not show collapse in the outer layer: additional the momentum injection appeared to indieate that the effects of momentum injection were confined to the near wall how. The energy content of the near-wall turbulence was found to shift to wavelengths of the order of magnitude of the roughness elements for all rough-walled cases. The additional momentum injection was found to decrease energy content in wavelengths corresponding to the roughness elements: while simultaneously adding energy at longer wavelengths. The structure of the turbulence in the outer layer was found to be largely unchanged by the addition of momentum injection, although there was evidenee of decreasing energy content in LSM modes and increasing energy content in VLSM modes.

The results are consistent in supporting the hypothesis that the effect of blowing could be modeled as a modification to the geometry through an increase in the height of the roughness elements. 'This support was observed through the additional displacement of the in imner-scaled mean velocity, the decreasing inner peak 
magnitude in the Reynolds stress, and the shift in near-wall energy content towards longer wavelengths.

\section{Acknowledgments}

This work was supported by a NASA Office of the Chief Technologist's Space Technology Research Fellowship (grant number NNX12AN20H) and by Commonwealth of Kentucky funding in association with a NASA EPSCoR award (identification number NNX10AV39A).

\section{References}

1 Adrian, R. C., Meinhart, C. D., and Tomkins, C. D. Vortex organization in the outer region of the turbulent boundary layer. f. Fluid Merh., 422:1-54, 2000.

2 Akinlade, O., Bergstrom, D., Tachie, M., and Castillo, L. Outer how scaling of smooth and rough wall turbulent boundary layers. Experiments in Fluids, 37:604 612, 2004.

"Bailey, S., Hultmark, M., Smits, A., and Schultz, M. Azimuthal structure of turbulenee in high Reynolds number pipe flow. J. Fluid Mech., 615:121 138, 2008.

${ }^{4}$ Bakken, O., Krogstad, P., Ashrafian, A., and Andersson, H. Roynolds number effects in the outer layer of the turbulent flow in a channel with rough walls. Phys. Fluids, 17, 2005.

${ }^{5}$ Bertin. J. J. and Cummings, R. M. Fifty years of hypersonics: where we've been, where we're going. Progress in Aerospace Sciences, 39.6:511-536, 2003.

${ }^{6}$ Castro, I. P. Rough-wall boundary layers: Mean flow universality. J. Fluid Mcch., 585:169 485, 2007.

7 Clanser, F'. The turbulent boundary layer. Advanced Applied Merhonics, 4:1-51, 1956.

${ }^{8}$ Guala, M., IIommema, S. E., and Adrian, R. J. Large-scale and very-large-scale motions in turbulent pipe flow. J. Fluid Mcch., 554:521 542, 2006.

9 Head, M. R. and Bandyopadhyay, P. New aspects of turbulent boundary-layer structure. \&. Fluid Mech.: $107: 297-337,1981$.

10 Hutchins, N. and Marusic, I. Jarge-seale influenese in near-wall turbulenee. Phit. Trans. R. Soc. A, $365: 647-664,2007$.

11 Jiménez, J. Turbulent flows over rough walls. Annu. Rev. Fluid Mcch., 36:173 196, 2004.

12 Jørgensen, $\mathrm{F}$. How to measure furbulence with hot-wire anemometers-a practical guide. Dantec Dynamies, P.O. Box 121: Tonsbakken 16-18, DK-2740) Skovlunde, Denmark, 012002.

$1:$ Kim, K. C. and Adrian, R. J. Very large-seale motion in the outer layer. Phys. Fluids, 11(2):417-422, 1999.

${ }^{14}$ Langelandsvik; L. I., Kunkel, G. J., and Smits, A. J. Flow in a commercial steel pipe. J. Fluid Mech.; $595(-1): 323-339,2008$.

15 Lee, J., Sung, II. J., and Krogstad, P. Direct numerical simulation of the turbulent boundary layer over a cube-roughened wall. I. Fluid Merh., 669:397-431, 2011.

16 McDonough, J., Yang, T., and Sheetz, M. Parallelization of a modern cfd incompressible turbulent flow code. Parallel Computational Fluid Dynamics: Advanced Numcrical Methods, Softwarc, and Applications, pages $473-479,2004$.

17 Monly, J. P. Developmenls in Smoolh Wall Turbulent Ducl Flows. PhD thesis, University of Melbourne: 2005.

18 Monty, J. P., Stewart, J. A., Williams, R. C., and Chong, M. Large-scale features in turbulent pipe and channel flows. J. Fluid Mech., 589:147 156, 2007.

${ }^{19}$ Monty, J., Hutchins, N., Ng, H., Marusie, 1., and Chong, M. A comparison of turbulent pipe, channel and boundary layer lows. J. Fluid Mech, 632:431-442, 2009.

20 Pope, S. B. Turbulent Flows. Cambridge University Press, 2000.

21 Raupach, M. R., Antonia, R., and Rjagopalan, S. Rough-wall turbulent boundary layers. Appl. Mech. Rev., 14:1 25, 1991.

22 Reshotko, E. Boundary-layer stability and transition. Annu. Rev. Fluid Mech., 8.1:311-349, 1976.

${ }^{23}$ Schneider, S. P. IIypersonic boundary-layer transition with ablation and blowing. AIAA Paper 3730: 2008.

21 Schultz, R. V. M. and Flack, K. Turbulence structure in boundary layers over periodic two- and threedimensional roughness. J. Fluid Mcch., 676:172, 2011.

25 Shockling, M. A., Allen, J. J., and Smits, A. J. Roughness effects in turbulent pipe flow. f. Fluid Merh., 
$564: 267285,2006$.

26 Tavoularis, S. Measurement in Fluid Mechanics. Cambridge Universily Press, 2005.

27 Townsend, A. A. The Structure of Turbulent Shcar Flow. Cambridge Lniversity Press, Cambridge, UK: 1976.

28 Voisinet, R. Inlluence of roughness and blowing on conpressible turbulent boundary layer flow. Technical report, Naval Surface Weapons Center, White Oak Lab, Silver Spring, MD, June 1979.

29 Zanoun, E. S., Durst, F., and II., N. Evaluating the law of the wall in two-dinnensional fully developed turbulent channel flows. Phys. Fluids, 15:3079 3089, 2003.

30 Zholl, J., Adrian, R. J., Balachandar, S., and Kendall, T'. M. Mechanisms for generating coherent packets of hairpin vortices in channel llows. J. Fluid Mech., 387:353-396, 1999. 